\title{
A Model for Enhancing Strategy Execution
}

\author{
Lanxing Yang \\ Department of Business Management, Jinan University, Guangzhou, China \\ Email: woaixiaofengzheng@163.com
}

How to cite this paper: Yang, L.X. (2019) A Model for Enhancing Strategy Execution. Journal of Human Resource and Sustainability Studies, 7, 360-367. https://doi.org/10.4236/jhrss.2019.73023

Received: April 3, 2019

Accepted: July 7, 2019

Published: July 10, 2019

Copyright $\odot 2019$ by author(s) and Scientific Research Publishing Inc. This work is licensed under the Creative Commons Attribution International License (CC BY 4.0).

http://creativecommons.org/licenses/by/4.0/

\begin{abstract}
Strategic management researches have always focused on the effects strategic decisions, and have fewer researches on strategy execution. The focus of this paper is on the ability to achieve strategic goals-strategy execution, and it has three conclusions. Firstly it redefines that strategy execution is the ability of achieving strategy; secondly, the factors which can have effect on strategy execution can be divided into three kinds: strategic management, attitude of members and mechanisms of organization; it finally puts forward corresponding suggestions from strategic management, personnel management and organizational mechanisms to provide guidance for enterprises.
\end{abstract}

\section{Keywords}

Strategy Execution, Influencing Factors, Strategic Management

\section{Introduction}

According to a research in 1999, there were about $70 \%$ of enterprises in the United States failed because of the organizational strategy execution [1], and organizations still face a $60 \%$ performance loss when implementing the strategy nowadays. Why is it so difficult to achieve strategic target for an organization? CEOs held that implementing strategies was more difficult than making a good strategy, and $66 \%$ of top managers said the strategy execution was not enough to achieve their strategies [2].

It is no doubt that the strategy execution of an organization determines whether the organization's strategy can be achieved, and it also determines the future of the organization. However, mainly existing researches about strategy execution focus on its' definition and actor in the path of improving performance, and there is not a common sense of what is strategy execution. What's more, the researches about what does influence strategy execution are so poor to build a systematic view in academe. So that is what motivates this paper to an- 
swer the two question: "What is strategy execution?" and "What are the factors that influence the strategy execution?", and then to provide corresponding suggestions for later scholars to develop the researches of strategy execution.

\section{The Concept of Strategic Execution}

Strategy execution rooted in strategic management theory, which includes strategic decisions' effects and the process of decision-making. And the latter includes two streams: strategy formulation and strategy execution [3]. The relationship is shown in Figure 1.

There are two main opinions on the definition of strategy execution in academe: a process or an ability. The scholars who hold that strategy execution is a process mainly agree the opinion of Bossidy, who proposed that strategy execution was a systematic process to achieve goals by asking questions, analyzing problems, and taking actions, while it was also a learning which needed to combine the reality with personnel and process to achieve the desired goals [4]. Some scholars, however, like Xueyunkui, believe that strategy execution is a comprehensive ability that use various resources and mechanisms to achieve strategic goals after making strategic choices, and it stems from the power to achieve goal when implement strategies [1].

In a word, no matter strategy execution is a process or an ability, its' aim is to achieve organizational strategy. But, an ability emphasizes the achievements of the strategic process, while scholars insist strategy execution is a process mainly emphasizes the link in it. So this paper takes strategy execution as an ability to achieve a given strategic goal, that is to say, strategy execution is an ability to transform strategic decisions into expected results by an effective system, organization, culture, and work-process and methods [5] [6]. And it is also the key to maintaining competitive advantages and the prerequisite for achieving organizational goals [7].

\section{The Influencing Factors of Strategic Execution}

Strategic execution is the necessary ability which determine whether the organizational strategy can be achieved, so the researches on its influencing factors can not only enrich the theory but also provide theoretical guidance for enterprises to build their own strategy execution. According to the existing opinions, there are mainly three factors that have effect on strategy execution: strategic management, personnel attitude and organizational management, as shown in Figure 2.

\subsection{The Attitude of Members}

Scholars believe that the core of strategy execution is people [8], and the attitude of members determines the motivation, thus determining the strategy execution of an organization. So how does the members' attitude affect the strategy execution? There are some factors. 


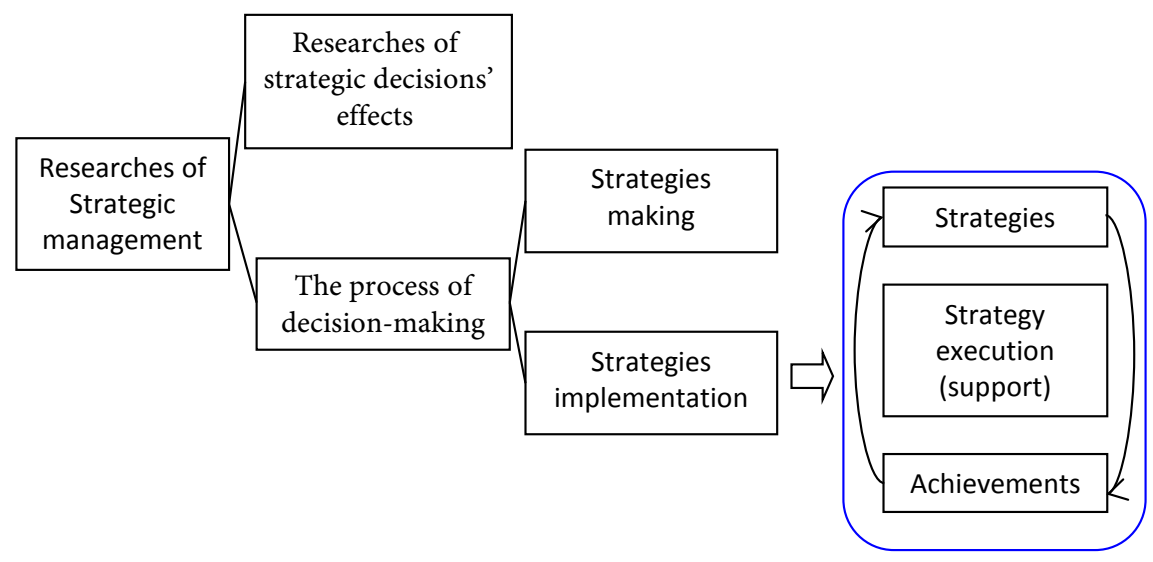

Figure 1. The origin of strategy execution.

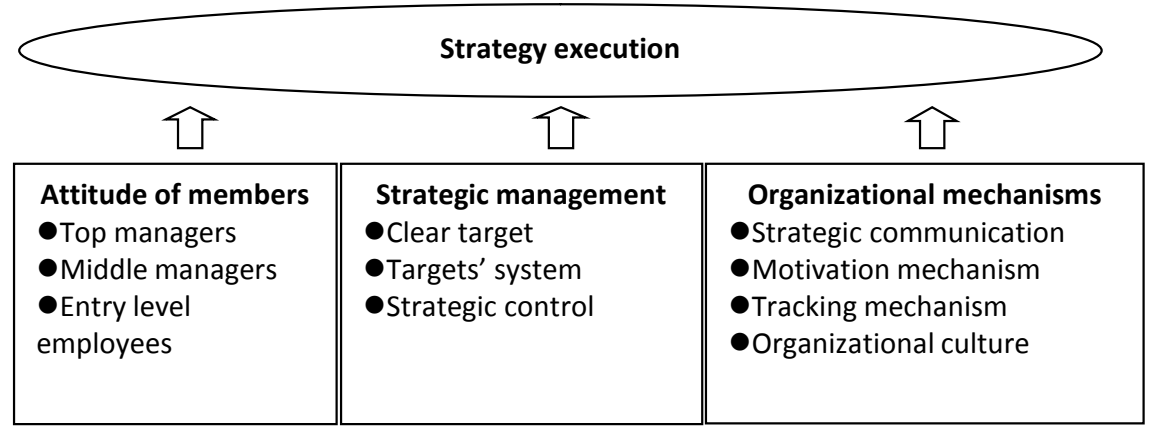

Figure 2. The influencing factors of strategy executive.

- Leaders' vision and belief of the organization can promote organizational strategy execution [9]. Vision, a concept of value, represents a higher expectation of future in work [10], and further leads the development of the organization. Only that the top managers have a clear knowledge of the vision and believe in it firmly, and then deliver the vision and beliefs to all the members actively, can the efforts of the team members focus on the organizational vision and thus form the strategy execution.

- The middle manager's understanding of strategy can facilitate the process of strategic decision-making and improve the strategy execution by optimizing the combination of kinds of resources [11] [12]. First of all, frequent strategic communication between middle managers and top managers is helpful to form their understanding of strategy, thereby improving strategy execution and make better performance. Secondly, compared with top managers, middle managers are closer to the market and production, so they can captures more information to improve the quality of strategic decision, and then improve strategy execution. Finally, as a bridge links the top managers and the entry level employees, the middle manager plays an important role that supporting and accelerating strategic communication in organization, and so that members can perform their duties in organizational construct and cooperate orderly to achieve the strategy. 
- Employees' recognition and commitment of the strategy is the decisive factor in the formation of strategy execution [13]. According to the theory of Management by Objectives (MBO), when employees feel that their role does take its own actor in the organizational strategy, they will be more encouraged and complete strategic goals more proactive, thereby improving strategy execution. In addition, when the members of the organization identify with the organizational strategy and share a strategic consensus, they will further form their commitment to the strategy to improve strategy execution and achieve a higher performance.

\subsection{The Strategic Management}

Strategy execution, the ability of an organization to achieve its strategy, starts with an organizational strategy and ultimately stands for strategic performance, that is to say, strategy is the origin of strategy execution. To be more specific, there should be a clear strategic objectives, specific targets system and strategic control.

- A clear strategic objectives. Kaplan [14] had proposed that the first element of strategy execution was a clearly declaration of the strategic goal. Ittner [15] also believed that identifying and confirming the organizational strategic objectives was the first thing to build strategy execution, because only a clear strategic goal could lead the organization insist its choice and allocate resources rationally to achieve maximum gains in the era of rapid development.

- A specific strategic targets system. In Kaplan and Ittner's view [14] [15], strategy execution is the ability to allocate resources and further make strategies employees' into actions. And to achieve such a transformations requires a specific strategic targets system. On the one hand, the specific strategic targets system can enable each member of the organization to get a clear understanding of the strategy, thereby enhancing employees' value-judgments to achieve optimal resource allocation, and finally improving strategy execution; on the other hand, a specific strategic targets system can make the boundaries of powers and responsibilities between members and departments clear, and then enhance strategic collaboration between departments to enhance the strategy execution.

- Timely strategic control actions. Pearce [16] believed that strategy execution should also include strategic control, that is to say, after making the strategy a targets system and allocating the resources, there should also be timely actions to enhance strategy execution, including tracking of internal and external environment and achievement of implementation, evaluation and encouragement of employee performance, and the continuous improvement of business activities. The goal of strategy execution is to coordinate the behaviors of members to achieve strategy, and after assignment of resources, all we can do is strategic control to make sure that whether the resources are useful as it should, whether the behaviors of members are strategically oriented, whether the performance achieved is consistent with strategy. So strategic con- 
trol is an important factor influencing strategy execution.

\subsection{The Mechanisms of Organization}

To form the strategy execution, what is necessary is the cooperation of members, so strategy execution will be reflected in the motivation, behaviors and performance of the members. And the link between strategy and members is organizational management mechanisms, which can integrate strategy and members to enhance the strategy execution. And the detailed relation can be shown in Figure 3.

- Strategic communication mechanism. When decomposing the strategy into a strategic targets system, it is necessary to deliver the strategy to all stakeholders of the organization, including employees, customers and suppliers [17]. Therefore, the construction of necessary strategic communication channels will affect the strength of organizational strategic consensus directly, thus affecting strategy execution.

- Organizational mechanisms to motivate members. Strategy execution based on the motivation and behaviors of the organization's members, so an effective mechanism of motivation can enhance strategy execution by influencing the motivation and performance of members [18].

- Organizational mechanisms of tracking. When implementing strategies, an accurate feedback can reconfirm the cognition of the subordinates on the strategy, thereby improving the strategy execution [19]. Because the feedback can provide members with information about their efforts and the next orientation they should work for, so they can confirm their roles in strategy and take next action fast.

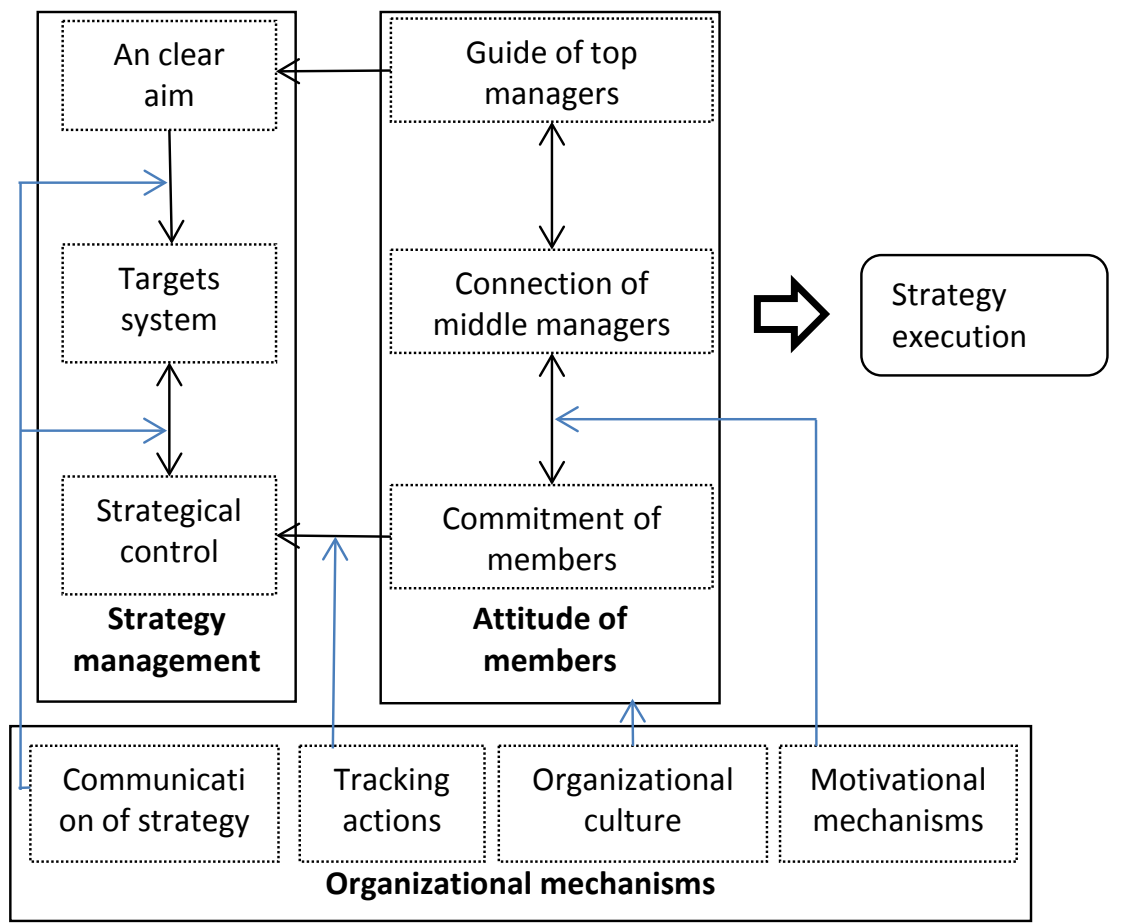

Figure 3. The factors influencing strategy executive. 
- Organizational mechanisms of the culture. The organizational atmosphere can influence the strategy execution [19], because the values, institutions and organizational behaviors' norms advocated by the organizational culture will affect the values and behaviors of members, and thus affect the strategy execution.

\section{Conclusions}

The direct reason influencing strategy execution is that the members of the organization cannot take actions as the organization expected; the second reason is that the members can not identify and promise the strategy; and the essential reason lies in the unreasonable design of organizational mechanisms. Because of the unreasonable design of managerial mechanisms, the strategic information cannot be delivered to everyone, and strategic consensus cannot be formed, and then members cannot make strategic choices to form strategy execution. Therefore, strategy execution of an organization should base on strategy, and take personnel as the core, with managerial mechanisms as means. That is to say, to form strategy execution, an organization should do something from three ways.

\subsection{Improve the Ability of Personnel Management}

- The comprehensive quality and leadership of top managers should be an example for subordinates;

- Not only improvements should be made from factors such as individual abilities, motivation, job design, organizational skills, and culture, and organizational mechanisms should also be designed for teams to achieve the evolution of strategic execution from individuals to teams, and further to organization [20];

- Ordinary employees should pay attention to the development of abilities, such as execution. Only in this way can we achieve the strategy shoulder to shoulder.

\subsection{Improve the Ability of Strategic Management}

- Firstly, in order to form strategy execution, the organization should have the ability to capture the information of the competitive environment to make a reasonable strategic goal;

- Secondly, it should also have the ability to decompose strategy into clear duties of employees through certain organizational structure and managerial tools;

- Finally, the ability of combining employee performance evaluation and organizational strategy will improve employee motivation, and then focus staff efforts on organizational strategy to achieve strategy execution [21].

\subsection{Enhance the Design of Organizational Mechanisms}

- An organization should improve the relevant institution to form good chan- 
nels of communication, clear assessment indicators, etc. [21], to make the strategy clear to be understood by personnel;

- An organization should also make assessment indicators of everyone clear [21] to let everyone know what should do and not to do;

- The organization should optimize the managerial mechanism, such as staff arrangement, motivations' management, limits' management, culture of teamwork, ect., to make sure that personnel are consistent with strategy.

\section{Conflicts of Interest}

The author declares no conflicts of interest regarding the publication of this paper.

\section{References}

[1] Xue, Y., Qi, D. and Wei, H. (2005) An Analysis of the Status Quo of Carrying-Out China's Enterprise Strategy, and of the Decisive Factors of the Executive Ability. Management World, 88-98.

[2] Olivier, A.J.S.E. (2018) Closing the Strategy Execution Gap in the Public Sector. International Journal of Public Leadership, 14, 6-32. https://doi.org/10.1108/IJPL-04-2016-0010

[3] Camillus, J.C. and Grant, J.H. (1980) Operational Planning: The Integration of Programming and Budgeting. Academy of Management Review, 5, 369-379. https://doi.org/10.5465/amr.1980.4288850

[4] Bossidy, L. (2002) Execution: The Discipline of Getting Things Done. Crown Business, New York.

[5] Stimie, J. and Vlok, P.J. (2016) A Mechanism for the Early Detection and Management of Physical Asset Management Strategy Execution Failure. South African Journal of Industrial Engineering, 27, 158-173. https://doi.org/10.7166/27-3-1651

[6] Barrick, M.R., Thurgood, G.R., Smith, T.A., et al. (2015) Collective Organizational Engagement: Linking Motivational Antecedents, Strategic Implementation, and Firm Performance. Academy of Management Journal, 58, 111-135. https://doi.org/10.5465/amj.2013.0227

[7] Xu, W., Sun, H., Wang, Z., et al. (2008) Dimension Structure and Measurement on Strategy Execution of Chinese Enterprises. China Industrial Economy, 10, 97-108.

[8] Kleinbaum, A.M. and Stuart, T.E. (2014) Inside the Black Box of the Corporate Staff: Social Networks and the Implementation of Corporate Strategy. Strategic Management Journal, 35, 24-47. https://doi.org/10.1002/smj.2090

[9] Van den Steen, E. (2018) Strategy and the Strategist: How It Matters Who Develops the Strategy. Management Science, 64, 4533-4551. https://doi.org/10.1287/mnsc.2017.2857

[10] Somech, A. and Drach-Zahavy, A. (2013) Translating Team Creativity to Innovation Implementation: The Role of Team Composition and Climate for Innovation. Journal of Management, 39, 684-708. https://doi.org/10.1177/0149206310394187

[11] Burgelman, R.A. (1994) Fading Memories: A Process Theory of Strategic Business Exit in Dynamic Environments. Administrative Science Quarterly, 39, 24-56. https://doi.org/10.2307/2393493

[12] Vilà, J. and Canales, J.I. (2008) Can Strategic Planning Make Strategy More Relevant 
and Build Commitment over Time? The Case of RACC. Long Range Planning, 41, 273-290. https://doi.org/10.1016/j.lrp.2008.02.009

[13] Dooley, R.S., Fryxell, G.E. and Judge, W.Q. (2000) Belaboring the Not-So-Obvious: Consensus, Commitment, and Strategy Implementation Speed and Success. Journal of Management, 26, 1237-1257. https://doi.org/10.1177/014920630002600609

[14] Kaplan, R.S. and Norton, D.P. (1996) Strategic Learning: The Balanced Scorecard. Strategy \& Leadership, 24, 18-24. https://doi.org/10.1108/eb054566

[15] Ittner, C.D. and Larcker, D.F. (2001) Assessing Empirical Research in Managerial Accounting: A Value-Based Management Perspective. Journal of Accounting \& Economics, 32, 349-410. https://doi.org/10.1016/S0165-4101(01)00026-X

[16] Pearce, J.A.A.R. (2008) Formulation, Implementation and Control of Competitive Strategy. 11th Edition, McGraw-Hill, New York.

[17] Nohria, N., Joyce, W. and Roberson, B. (2003) What Really Works. Harvard Business Review, 81, 42-52.

[18] Slater, S.F. and Olson, E.M. (2000) Strategy Type and Performance: The Influence of Sales Force Management. Strategic Management Journal, 21, 813-829. https://doi.org/10.1002/1097-0266(200008)21:8<813::AID-SMJ122>3.0.CO;2-G

[19] Lee, E. and Puranam, P. (2016) The Implementation Imperative: Why One Should Implement Even Imperfect Strategies Perfectly. Strategic Management Journal, 37, 1529-1546. https://doi.org/10.1002/smj.2414

[20] Levenson, A. (2018) Using Workforce Analytics to Improve Strategy Execution. Human Resource Management, 57, 685-700. https://doi.org/10.1002/hrm.21850

[21] Neilson, G.L., Martin, K.L. and Powers, E. (2008) The Secrets to Successful Strategy Execution. Harvard Business Review, 86, 60-70. 